PRINT ISSN 1119-8362

Electronic ISSN 1119-8362
Full-text Available Online at

https://www.ajol.info/index.php/jasem

http://ww.bioline.org.br/ja
J. Appl. Sci. Environ. Manage.

Vol. 25 (5) 823 - 827 May 2021

\title{
2-D Electrical Resistivity Imaging Survey for Lithological Assessment at Igwete Primary School, Amai, South-South Nigeria
}

\author{
*ENEBELI, VC; OKORAFOR, CN; KOLAGBODI, RE
}

\author{
Department of Energy and Petroleum Studies, Novena University, Ogume, Delta State, Nigeria \\ *Corresponding Author Email: enebelivc@ gmail.com; Tel: +2348138559321; Other Authors Email and Phone: \\ rekolagbodi@hotmail.com; Tel:08136889328; rekolagbodi@hotmail.com; Tel:08136889328
}

\begin{abstract}
Electrical Resistivity Imaging (ERI) is a useful near-surface imaging technique, which mainly include data acquisition, numerical modelling and tomographic inversion. Within the study area, only one dimensional (1-D) Electrical Resistivity survey has been carried out for Geophysical investigations. Therefore, 2-D ERI survey was carried out at the Igwete Primary School, Amai to provide electrical picture of the subsurface from which discrete bodies and lithology are better revealed vertically and in lateral extent. The 2-D ERT survey data were acquired using the Petrozenith Earth Resistivity meter while employing the Wenner electrode array. The 2-D apparent resistivity data were inverted to obtain true resistivities of the subsurface using res2dinv software running on personal computer. The subsurface resistivity models were displayed as pseudo sections and inverted resistivity section in the form of colour shaded contour maps. The inverse resistivity model images indicate that at a lateral extent in the range (15.00-21.00) $\mathrm{m}$ and (33.00-39.00) $\mathrm{m}$, anomalies suspected to be gravel mixed with sand is in place with resistivities of about (254.00-948.00) $\Omega \mathrm{m}$. From the geologic section we can infer that a geological formation is observed at a lateral position of (27.00-32.00) $\mathrm{m}$ of resistivity in the range (90.00-93.00) $\Omega \mathrm{m}$. This structure is inferred to be a clay pocket. The sandy nature of the formation requires that underground water development be sought for at $(9.00-15.00) \mathrm{m}$ over a depth (2.30-8.00) $\mathrm{m}$ in the sandy environment. Results of 2D resistivity imaging has helped to delineate the lithology which comprise mainly of; sand, sandy clay, clayey sand depositional environment. The resistivity of these lithology falls in the range (90.00-93.00) $\Omega \mathrm{m}$ with depth to formation of about $(2.30-6.00) \mathrm{m}$.
\end{abstract}

DOI: https://dx.doi.org/10.4314/jasem.v25i5.21

Copyright: Copyright (C) 2021 Enebeli et al. This is an open access article distributed under the Creative Commons Attribution License (CCL), which permits unrestricted use, distribution, and reproduction in any medium, provided the original work is properly cited.

Dates: Received: 20 March 2021; Revised: 27 April 2021; Accepted: 07 May 2021

Keywords: Resistivity, lithology, geologic section, geophysical investigation, imaging technique

Geophysical methods are employed in the exploration of geological structures and are implemented in a wide range of applications ranging from building, groundwater investigation to the inspection of dams and dike Klimis et al., (1999); Othman, (2005); Savaidisi et al., (1999); Soupios et al., (2006), aiming towards the exploration of geological structure and the determination of physical parameters of the rock formations/units. Delineation of subsurface cavities and shallow weathered zone using geophysical methods has gained wide interests in the past few decades (Abu-Shariah, 2009; Vachiratienchai et al., 2010). Electrical geophysical methods are used to determine the electrical resistivity of the earth's subsurface. The resistivity distribution of the subsurface can be interpreted in terms of soil characteristics and/or rock type (lithology) and geological structure. Electrical Resistivity Imaging (ERI) is a near-surface electrical geophysical method that uses direct current to measure the earth's resistivity. It provides $2 \mathrm{D}$ and $3 \mathrm{D}$ images of the variation in electrical resistivity using electrodes typically placed on the ground surface. Zhu et al.,
(2011) adopted a range of ERI methods (including time-lapse approaches) to locate karst conduits, and combined ERI and GPR to detect fractures and conduits in karst (Carrière et al., 2013; MartínezMoreno et al., 2014). The use of electrical resistivity tomography applied to environmental studies is well documented (Bernstone et al., 2019). 2-D Electrical Resistivity Imaging survey using the Wenner array was carried out at Igwete Primary School, Amai, South-South Nigeria with the research objective of surveying the lithological profile of the study area.

\section{MATERIALS AND METHODS}

Site Description/Location: The Study location is Igwete Primary School in Ishikaguma quarters of Amai kingdom, Ukwuani Local Government Area of Delta State. It is in the Southern part of Nigeria known as the Niger Delta and lies within latitudes $\left(5.96^{\circ}\right.$ to $\left.6.04^{0}\right) \mathrm{N}$ and longitudes $\left(6.48^{0}\right.$ to $\left.6.59^{\circ}\right) \mathrm{E}$ with an elevation of about $23.00 \mathrm{~m}$ above sea level as depicted in Figure 1. The study location is bounded on the North by Obiaruku, on the South by Ezeonum, on the 
West by Arhagba and on the East by Ogume. Amai has two major roads which are tarred. These are the Obiaruku -Amai road and Ogume-Amai road with some network of roads that are not tarred. Amai is also home to the Novena University and the Konum farms limited. The occupation of her settlers is mainly farming. The line co-ordinates for the study and survey locations are presented in table1 and figure 1 respectively.

Table 1 Profile Line Co-ordinates

\begin{tabular}{llll}
\hline Profile Line & Co-Ordinates & Latitude & Longitude \\
\hline \multirow{2}{*}{ ERI LINE } & Begin coordinate & $\mathrm{N}^{\circ} 45^{\prime} 05.1^{\prime \prime}$, & E006 $^{\circ} 12^{\prime} 15.4^{\prime \prime}$ \\
& End coordinate & $\mathrm{N}^{\circ} 45^{\prime} 06.7^{\prime}$ & E006 $^{\circ} 12^{\prime} 17.5$ \\
\hline
\end{tabular}

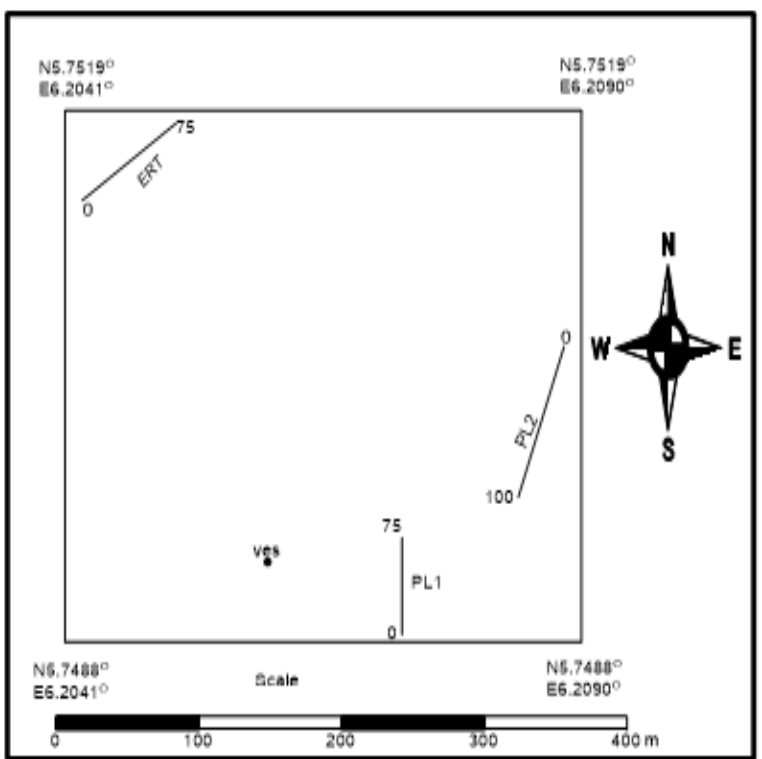

Fig 1: AMAI Geophysical survey location map for the ERI profile line

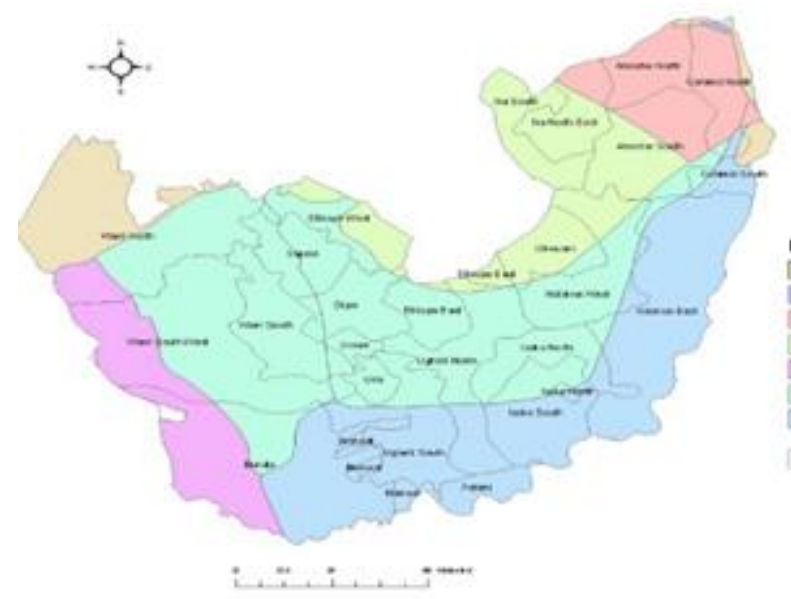

Fig 2: Map showing the geological description of the study area.

Geological Feature: The three major depositional environments typical of most deltaic environment are the marine, mixed and continental deposits. In Amai, the topmost layer of the soil contains humus content. Below the humus soil is a massive bed of lateritic soil which increases downward from the topsoil. It is dark brown and after a further depth it became reddish brown. This massive bed of lateritic soil is inferred to be a feature of Benin formation. The major lithological composition of the study area are clays, sands (coarse and fine), sandy clays and gravels. Amai kingdom is within the Niger Delta basin. However, in Amai kingdom, the topsoil contains humus and a bed of lateritic soil beneath it which is a feature of the Benin formation (Oseji, 2013).

2-D Electrical Imaging Surveys: One- dimensional (1D) resistivity sounding surveys carryout measurements with different spacing between electrodes but with a common center. The data is usually plotted on a sounding curve. 1-D models are probably too inaccurate for most areas where there are significant lateral and vertical variations in resistivity. As such, this method does not take into account horizontal changes in the subsurface resistivity. A more accurate model of the subsurface is a twodimensional (2-D) model where the resistivity changes in the vertical direction as well as in the horizontal direction along the survey line. In this case, it is assumed that resistivity does not change in the direction that is perpendicular to the survey line. In many situations, particularly for surveys over elongated geological bodies, this is a reasonable assumption. In many geological situations, 2-D electrical imaging surveys can give useful results that are complementary to the information.2-D electrical survey should be integrated with other geophysical methods to provide background information of the subsurface. 2-D electrical survey used in conjunction with seismic, GPR or VLF surveys as they provide complementary information about the subsurface.

Theory: All resistivity methods employ an artificial source of current which is introduced into the ground through point or long lines contacts. The procedure is to measure potentials at other electrodes in the neighborhood of the current flow. Electrical methods are based on the resistivity or its inverse; this is the conductivity of the material.

From surface potential we have,

$\mathrm{U}(\mathrm{r})=\frac{I \rho}{2 \pi r}$

Where; $\mathrm{I}=$ current, $\rho=$ resistivity, $\mathrm{r}=$ distance between electrodes.

A single point current source can be achieved in theory by placing a corresponding current source at infinity. 
Determination of subsurface resistivities requires knowledge of the potential distribution in addition to the input current. Given two current electrodes A and $\mathrm{B}$ in Figure 3, when we apply equation 1, the potential at arbitrary point $\mathrm{M}$ is

$$
\mathrm{U}_{\mathrm{m}}=\frac{I \rho}{2 \pi}\left[\frac{1}{r 1}-\frac{1}{r 2}\right]
$$

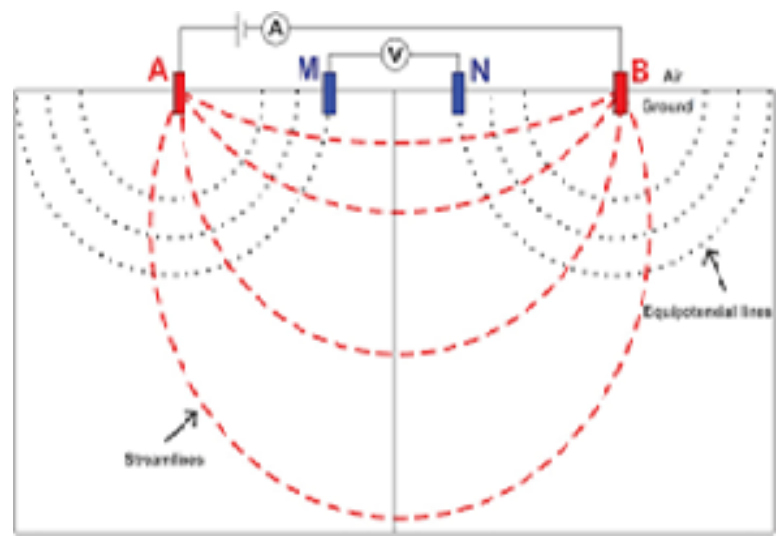

Fig 3: Distribution of current and potential lines for two current electrodes at the surface of a homogenous half-space source

To measure potential difference, two electrodes are needed. Theoretically, the injecting electrodes A and $\mathrm{B}$ could be used to measure the response signal. A dedicated pair of electrodes for measuring voltage difference completes four-electrode array commonly used in DC resistivity surveying. Subtracting the potential at point $\mathrm{M}$ gives the potential difference $\Delta \mathrm{U}$ between $\mathrm{M}$ and $\mathrm{N}$ :

$\Delta U=\frac{I \rho}{2 \pi}\left[\frac{1}{r 1}-\frac{1}{r 2}-\frac{1}{r 3}+\frac{1}{r 4}\right]=\frac{I \rho}{K}$

Where $r_{3}$ is the distance between $\mathrm{M}$ and $\mathrm{A}, \mathrm{r}_{4}$ is the distance $\mathrm{N}$ and $\mathrm{B}$. Since $\mathrm{K}$ only contains distance between electrodes, it is called the geometric Factor which depends on the relative distribution of electrodes. On rearranging equation 2 , we obtain

$\rho=K \frac{\Delta U}{I}$

For an inhomogeneous earth, this equation will produce values that vary according to the geometrical arrangements of electrodes on the surface. Values obtained from equation (4) or an inhomogeneous underground are referred to as apparent resistivity, $\rho_{\text {a }}$.

\section{MATERIALS AND METHODS}

Geophysical resistivity methods are based on the response of subsurface materials to the flow of electric currents. In these methods, an electric current is injected into the ground and two potential electrodes are used to measure the resulting potential difference between the current electrodes and thus allowing for the measurement of the electrical impedance of the subsurface. The resistivity of the soil is a function of porosity, permeability, ionic content of the pore fluids, and clay mineralization.

All resistivity methods employ an artificial source of current which is injected into the ground through point electrodes. In a field survey, the resistivity of the subsurface is measured by passing a current through the ground. Four metal electrodes are planted into the ground. An electric current (10mA to $3 \mathrm{~A}$ ) is injected into the ground using electrodes $C_{1}$ and $C_{2}$ designated as current electrodes. The resulting voltage difference at two points on the ground surface is measured using two electrodes, $\mathrm{P}_{1}$ and $\mathrm{P}_{2}$, the potential electrodes.

A preliminary survey was carried out on the survey location. The terrain was observed for any topological effects in terms of sharp elevation contrasts along a chosen profile.

Field Design: The following survey parameters were then planned for:

Measuring instrument: Petrozenith Earth Resistivity meter.

Electrode configuration: Wenner.

Profile length: $\quad 75 \mathrm{~m}$

Electrode Spacing: $\quad 3 \mathrm{~m}$

Begin Coordinates: $\quad$ N5 ${ }^{\mathrm{O}} 45^{\prime} 05.1^{\prime}$, E006 ${ }^{\mathrm{O}} 12^{\prime}$

15.4 ,'

End Coordinates: $\quad \mathrm{N} 5^{\circ} 45^{\prime} 06.7^{\prime}$, , E006 ${ }^{\circ} 12^{\prime}$

17.5 ,

Profile orientation: East-West.

Data Acquisition: The field data acquisition was carried out after a reconnaissance visit to the study area. The co-ordinate values of the profile were collected using Germaine Geographical Positioning System (GPS). Planting of electrodes numbering 0-25 were fixed into the ground at selected intervals of $3 \mathrm{~m}$ along the profile line. The unit electrodes spacing was $3 \mathrm{~m}$ to ensure high resolution from the subsurface geoelectrical image. The profile length was $75.00 \mathrm{~m}$. The maximum electrodes spacing was $15.00 \mathrm{~m}$, giving the maximum depth of investigation at about $7.70 \mathrm{~m}$.

2-D ERI survey data were acquired using the Petrozenith Earth Resistivity meter while employing the Wenner electrode array. For the first measurement, $\mathrm{n}=1, \mathrm{a}=5, \mathrm{~K}=3.142$ which stands for serial number 1. The four electrodes are positioned at $(0 \mathrm{~m}, 3 \mathrm{~m}, 6 \mathrm{~m}$ and $9 \mathrm{~m})$, which corresponds to the $\left(\mathrm{C}_{1}, \mathrm{P}_{1}, \mathrm{P}_{2}, \mathrm{C}_{2}\right)$ positions for the current $\left(\mathrm{C}_{1}\right.$ and $\left.\mathrm{C}_{2}\right)$ and potential electrodes $\left(\mathrm{P}_{1}\right.$ and $\left.\mathrm{P}_{2}\right)$ on the particular profile. The 
next serial number 2 , is a forward shift of electrodes positions by $5 \mathrm{~m}$ each. The electrodes assume the new positions ( $3 \mathrm{~m}, 6 \mathrm{~m}, 9 \mathrm{~m}$, and $12 \mathrm{~m})$. However, the $\mathrm{P}_{1}$ and $\mathrm{P}_{2}$ difference of $3 \mathrm{~m}$ is maintained throughout the measurements. $75 \mathrm{~m}$ profile length is observed for twenty-six (26) electrodes. In each case, the circuitry is completed by connecting the electrodes to the Pasi Earth Resistivity meter via single core cables. The resistance of the formation was measured which were then transformed to apparent resistivity through the transformation equation.

$\rho \mathrm{a}=\mathrm{KR}$

Where $\mathrm{K}=\mathrm{na}$; $\rho$ a is apparent resistivity, $\mathrm{R}$ is resistance, $\mathrm{K}$ is Geometrical factor

2-D Data Inversion: The field operation generated 2$\mathrm{D}$ data set of apparent resistivities. These 2-D data sets are collated and inverted separately using the RESZDINV software on a personal computer to obtain 2-D models of the line subsurface resistivities. The subsurface resistivity models were displayed as pseudo sections and inverted resistivity section in the form of colour shaded contour maps. In the displayed graphic, the upper figure is a pseudo section drawn with the raw field data, the middle is a pseudo section drawn with the computer generated apparent resistivity data, while the lower figure is the true subsurface model drawn from the computed generated apparent resistivity. Ten iterations were carried out at Abs. error, $15.00 \%$.

\section{RESULTS AND DISCUSSION}

Field data obtained from the instrument readings at each survey lines were recorded in a data sheet. The geometrical factor " $\mathrm{K}$ " for each sequence of measurement "n" was computed using equation (5). This was then used to multiply the resistance values read from the instrument to obtain the apparent resistivity. The true resistivity figure was scan to identify isolated resistivity anomalies. The anomalous areas were inferred to be sandy clay and clayey sand deposits in the sand environment being electrically imaged. At a lateral extent in the range (15.00-21.00) $\mathrm{m}$ and (33.00-39.00) $\mathrm{m}$, anomalies suspected to be gravel mixed with sand is in place with resistivities of about (254.00-948.00) $\Omega \mathrm{m}$. From the geologic section we can infer that a geological formation is observed at a lateral position of (27.00-32.00) $\mathrm{m}$ of resistivity in the range (90.00-93.00) $\Omega \mathrm{m}$. This structure is inferred to be a clay pocket. Because of the sandy nature of the formation, underground water development can be sought for at (9.00-15.00) m over a depth (2.30-8.00) $\mathrm{m}$ in the sandy environment. The subsurface materials are presented in the form of geologic section drawn in surfer 13.0 software window, figure 5 .

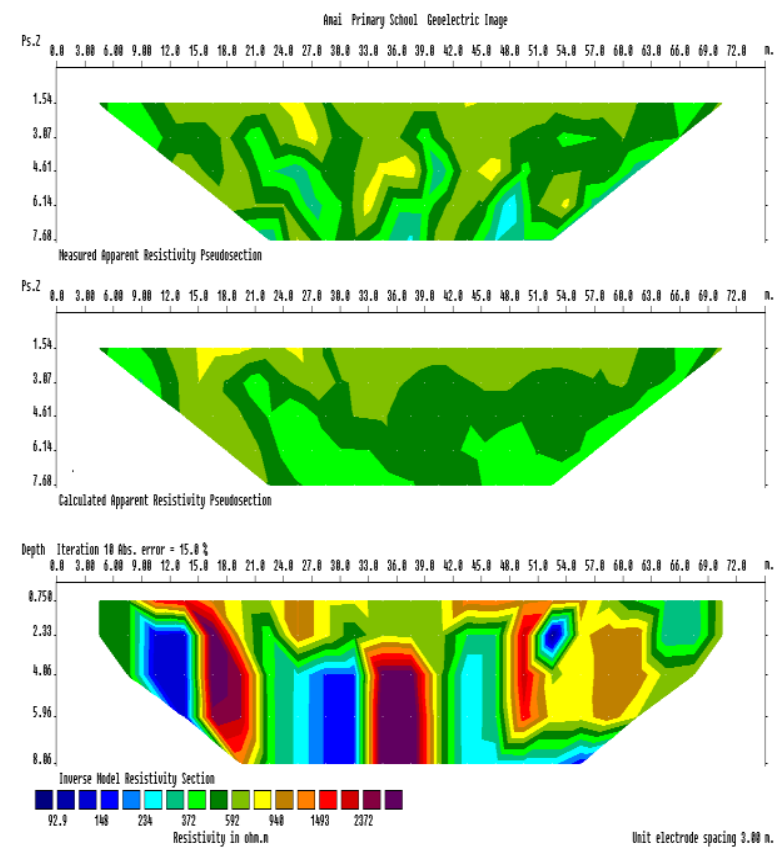

Fig 4: Igwete - Amai 2-D ERI inverse model image

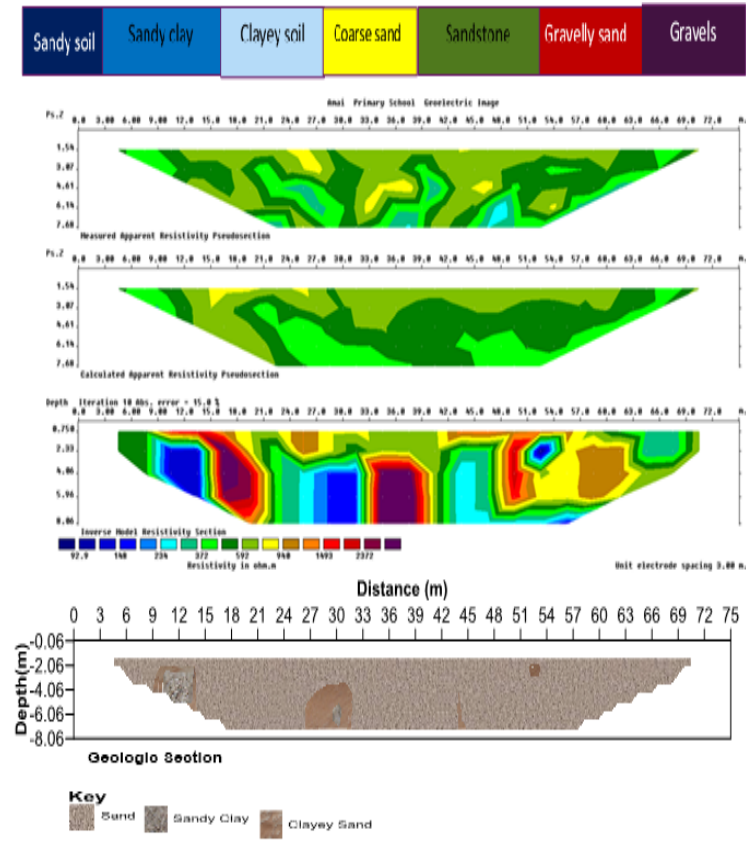

Fig 5: Igwete-Amai 2-D ERI inverse model image geologic section

Conclusion: The 2-D Electrical Resistivity imaging survey provides electrical picture of the subsurface from which discrete bodies are better revealed. Both vertical and lateral extents are made visible. The 2-D Resistivity Imaging has helped delineate the lithology to comprise mainly of; sand, sandy clay, clayey sand 
depositional environment. The resistivity of these lithology falls in the range (90.00-93.00) $\Omega \mathrm{m}$ with depth to formation of about $(2.30-6.00) \mathrm{m}$. There is no flooding threat.

Acknowledgement: The authors wish to acknowledge the kind support of Mr. Eremionkhale Paul during the field exercise for data acquisition.

\section{REFERENCES}

Abu-Shariah., MII (2009). Engineering Geology, 105, pp. 239-244

Bernstone, T. Dahlin, T. Ohlsson, and W. Hogland (2000). "DC-resistivity mapping of internal landfill structures: two pre-excavation surveys," Environ. Geol. 39, 3-4, 360-371.

Carrière, SD; Chalikakis K; Sénéchal G; Danquigny C; Emblanch C (2013). Combining electrical resistivity tomography and ground penetrating radar to study geological structuring of karst unsaturated zone. J. Appl. Geophys 94:31-41.

Klimis, NS; Papazachos, CB; Efremidis, ChF (1999). Determination of the behavior of a Sedimentary rock mass: Comparison of measured static and dynamic properties proceedings, $9^{\text {th }}$ int.Conf. On Rock mechanics (Paris France).

Martínez-Moreno, FJ; Galindo-Zaldívara J; Pedrera A; Teixido T; Ruano P; Peña JA; González-Castillo L; Ruiz-Constán A; López-Chicanoa M; MartínRosalesa W (2014). Integrated geophysical methods for studying the karst system of Gruta de las Maravillas (Aracena, Southwest Spain). J Appl. Geophys 107:149-162

Oseji, JO (2013). Hydrogeophysical investigation of groundwater resources in Amai Kingdom in Ukwuani local government area of Delta State. Res. J. Agric. Environ. Manage. 2(5), 104-114.
Othman, AAA (2005). Constructed geotechnical characteristics of foundation beds by seismic measurements. J. Geophysics Eng. (2) 6-38.

Savaidisi, A; Tsokas, G; Soupios, P; Vargemezis, G; Manakou, M (1999). Geophysical prospecting in the Krousovitis dam Seismic and resistivity geophysical methods. J. Balkan Geophys. SOC. (2) $128-37$.

Soupios, P; Papazachos, CB; Vergemesis, G., Savvaidis, A (2006). In Situ geophysical investigation to evaluate dynamic soil properties at the Ibrionas Dam, Northern Greece, Proc. $2^{\text {nd }}$ int. conf. advances in Mineral Resources Management and Environmental Geotechology (Harnia, Crete, Greece, 25-27, Sept-2006). (Heliotopos Conferences) pp 149-56

Vachiratienchai, B; Songkhun, S; Weerachai (2010). A hybrid finite difference-finite element method to incorporate topography for 2D direct current (DC) resistivity modeling. Physics of the Earth and Planetary Interiors, 183. 426-434

Zhu, J; Currens, JC; Dinger JS (2011). Challenges of using electrical resistivity method to locate karst conduits - a field case in the Inner Bluegrass Region, Kentucky. J. Appl. Geophys 75:523-530. 